Article

\title{
Synthesis and Photocontrolled Supramolecular Self-Assembly of Azobenzene-Functionalized Perylene Bisimide Derivatives
}

\author{
Weikang Ling ${ }^{1}$, Xiaoxiao Cheng ${ }^{1}$, Tengfei Miao ${ }^{1}$, Shuangshuang Zhang ${ }^{1}$, Wei Zhang ${ }^{1, *(1)}$ \\ and Xiulin $\mathrm{Zhu}^{2}$ \\ 1 Suzhou Key Laboratory of Macromolecular Design and Precision Synthesis, Jiangsu Key Laboratory of \\ Advanced Functional Polymer Design and Application, State and Local Joint Engineering Laboratory for \\ Novel Functional Polymeric Materials, College of Chemistry, Chemical Engineering and Materials Science, \\ Soochow University, Suzhou 215123, China \\ 2 Global Institute of Software Technology, No 5. Qingshan Road, Suzhou National Hi-Tech District, \\ Suzhou 215163, China \\ * Correspondence: weizhang@suda.edu.cn; Tel.: +86-512-65884243; Fax: +86-512-65882787
}

Received: 6 May 2019; Accepted: 2 July 2019; Published: 3 July 2019

\begin{abstract}
Azobenzene (Azo) units were successfully introduced into perylene bisimide (PBI) structures in order to realize the photocontrolling of the morphology of the supramolecular assembly of PBI by a photoisomerization process. A total of three Azo-functionalized perylene bisimide derivatives (PBI1, PBI2, and PBI3) with different alkyl chain lengths were designed and synthesized by imidization of 3,4,9,10-perylene tetracarboxylic dianhydride with the corresponding amines. The structures of these compounds were characterized by proton nuclear magnetic resonance $\left({ }^{1} \mathrm{H}\right.$ NMR) and matrix-assisted laser desorption ionization time-of-flight mass spectrometry (MALDI-TOF-MS). The photoisomerization behaviors of Azo units in PBIs were investigated using ultraviolet-visible (UV-VIS) absorption spectroscopy, which were obviously effected by solvents and the alkyl chain length. Furthermore, the photoisomerization of Azo units has the obviously regulatory effect on the morphology of supramolecular assembly of PBIs, especially for the medium-length alkyl chain-linked Azo-functionalized PBI derivative (PBI2). This research realized the photocontrolling of the morphology of the supramolecular assembly of PBI derivatives by photoisomerization of Azo units.
\end{abstract}

Keywords: perylene bisimide; azobenzene; supramolecular assembly; photoisomerization; morphology control

\section{Introduction}

Perylene tetracarboxylic acid bisimides (PBI) have attracted considerable attention on account of their luminescence [1-6], n-type semiconductor [7-11] properties in the past few decades, and have found a use as applications in sensors [12], lasers [13], drug release [14], organic electronic devices [15], supramolecular self-assemblies [16], and so on. The strong $\pi-\pi$ stacking interactions between the PBI core composed of five condensed benzene rings endow with the formation of supramolecular structures by the intermolecular self-assembly process [17-19]. Furthermore, introduction of amide structure to the PBI core provides hydrogen bonding interaction between PBI building blocks. The cooperation of $\pi-\pi$ stacking, hydrogen bonding, hydrophobic/hydrophilic interactions, and the van der Waals force drives the formation of the PBI-based supramolecular nanostructures [20-23]. Recently, much more efforts have been done on the controlling of the local $\pi$-stacking arrangements of PBI units, which is typically called "face-to-face" H-aggregates and "head-to-tail" J-aggregates. H-aggregates 
and J-aggregates show different electroptical properties in which H-aggregates commonly present low fluorescence emission and high n-type carrier mobility, but J-aggregates demonstrate highly fluorescence emission along with obvious red-shift absorption [24]. Significant progress has been achieved for the transformation of $\mathrm{H}$ - and J-aggregates. Würther and co-workers first reported the formation of J-aggregates by supramolecular design principles [25]. Furthermore, they presented the successful transformation from $\mathrm{H}$ - to J-aggregates of PBI driving by hydrogen-bond directed complexation between melamine and cyanurate units [26]. More recently, Würther et al. designed one-dimensional brickwork J-aggregates of PBI with thermotropic liquid-crystalline [27]. The formation of J-aggregates of PBI can also be produced by other strategies, such as the addition of the inducer [28], introduction of steric alkyl substituents [29], and so on. Meanwhile, the PBI-based helical nanofibers can be produced by a supramolecular assembly of chiral PBI derivative or an achiral one in chiral solvent [30]. The different types of aggregates result in a different morphology of supramolecular nanostructures, demonstrating different electro-optical properties.

Azobenzene (Azo) is one of the classical photoresponsive compounds, the drastic changes of which both in the structure and properties can be caused by the reversible trans-cis isomerization process. This special property of Azo has been used to regulate the morphology of aggregates [31,32], supramolecular chirality [33-35], and gelation property [36,37]. Ajyaghosh et al. reported an Azo-functionalized phenyleneethynylene derivative, the aggregate morphology of which changed from the initially formed nanodots to supramolecular rods by trans-cis photoisomerization of the Azo unit [38]. Yagai and co-workers reported the supramolecular assembly of a chiral Azo dimer, whose morphology and chirality can be controlled by photoisomerization of Azo moiety [39]. Our group reported the morphology and chirality control of supramolecular structure of achiral Azo-containing polymers in the chiral solvent by reversible trans-cis isomerization of Azo chromophore [40]. Nevertheless, introducing Azo units into PBI structure and investigating the effect of the trans-cis photoisomerization process on the morphology of PBI aggregates is still rare so far. Klaus et al. designed a rigid polyphenylene dendrimer containing Azo, pyridyl, and ethynyl entities, which controlled over molecular size, intramolecular energy transfer between Azo and PBI by reversible photoisomerization of Azo units [41]. Tao and co-workers introduced the Azo groups into the bay-position of the PBI, and they found the morphological evolution of the nanostructures from ribbons to spheres driven by the trans-cis isomerization of Azo units with $365 \mathrm{~nm}$ wavelength light irradiation [42].

Herein, we designed and synthesized a series of symmetrical Azo-functionalized PBI derivatives with Azo groups at both sides of a perylene ring. The supramolecular nanostructures were formed driven by the cooperation of $\pi-\pi$ stacking of perylene and Azo groups, hydrogen bonding interaction and the van der Waals force. The effects of different alkyl chain lengths on the Azo photoisomerization behavior and the further influence on the PBI nanostructures were also investigated.

\section{Experiment}

\subsection{Materials}

p-Anisidine (99\%, Macklin, Shanghai, China), phenol (99\%, Enox, Jiangsu, China), sodium nitrite (99\%, Enox, Jiangsu, China), 1,6-dibromohexane (98\%, Adamas, Shanghai, China), methyl gallate (99\%, Sinopharm Chemical Reagent Co., Ltd., Shanghai, China), ethylenediamine (99\%, Sinopharm Chemical Reagent Co., Ltd., Shanghai, China), 3,4,9,10-perylenetetracarboxylic dianhydride (98\%, D\&B, Shanghai, China), zinc acetate (99\%, Sinopharm Chemical Reagent Co., Ltd., Shanghai, China), imidazole (99\%, Sinopharm Chemical Reagent Co., Ltd., Shanghai, China), 4-acetamino phenol (98\%, TCI, Shanghai, China), 1-bromohexane (99\%, Macklin, Shanghai, China), 1-bromododecane (98\%, Macklin, Shanghai, China), and thionylchloride (99\%, Sinopharm Chemical Reagent Co., Ltd., Shanghai, China) were used as received. All solvents and other chemical reagents were purchased from Shanghai Chemical Reagent Co., Ltd. (Shanghai, China) and used as received without any further treatment. 


\subsection{Synthesis of PBI1, PBI2, and PBI3}

PBI1, PBI2, and PBI3 were synthesized according to the procedures in Scheme 1. The compounds a-d were synthesized according to a method similar to that reported by Xie et al. [43] and conformed by proton nuclear magnetic resonance $\left({ }^{1} \mathrm{H}\right.$ NMR) spectra.

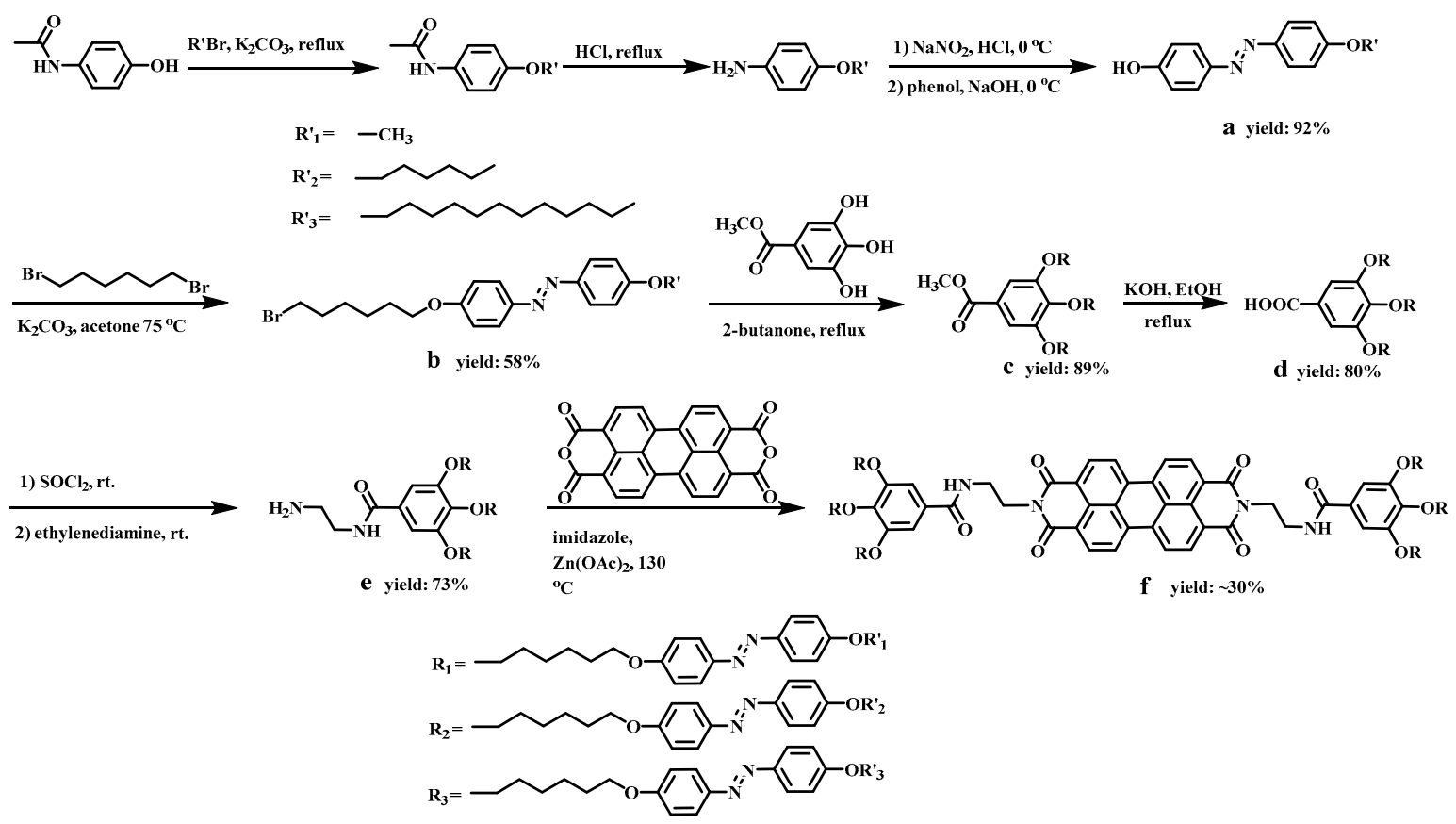

Scheme 1. Synthetic routes of perylene tetracarboxylic acid bisimides PBI1, PBI2, and PBI3.

Compound 1a: Yield 92\%. ${ }^{1} \mathrm{H}$ NMR $\left(300 \mathrm{MHz}\right.$, DMSO- $d_{6}$ ) (Figure S1) $\delta 10.18(\mathrm{~s}, 1 \mathrm{H}, \mathrm{ArOH}), 7.78$ $(\mathrm{dd}, J=19.5,8.9 \mathrm{~Hz}, 4 \mathrm{H}, A r H), 7.01(\mathrm{dd}, J=53.5,8.9 \mathrm{~Hz}, 4 \mathrm{H}, A r H), 3.85\left(\mathrm{~s}, 3 \mathrm{H}, \mathrm{OCH}_{3}\right)$. Compound 2a: Yield 66\%. ${ }^{1} \mathrm{H}$ NMR (300 MHz, DMSO- $d_{6}$ ) (Figure S2) $\delta 10.16(\mathrm{~s}, 1 \mathrm{H}, A r O H), 7.77(\mathrm{dd}, J=14.8,8.9 \mathrm{~Hz}$, $4 \mathrm{H}, A r H), 7.00(\mathrm{dd}, J=47.7,8.9 \mathrm{~Hz}, 4 \mathrm{H}, A r H), 4.05\left(\mathrm{t}, J=6.5 \mathrm{~Hz}, 2 \mathrm{H}, \mathrm{OCH}_{2}\right), 1.88-1.32\left(\mathrm{~m}, 8 \mathrm{H}, \mathrm{CH}_{2}\right)$, $0.88\left(\mathrm{t}, J=7.0 \mathrm{~Hz}, 3 \mathrm{H}, \mathrm{CH}_{3}\right)$. Compound 3a: Yield 91\%. ${ }^{1} \mathrm{H}$ NMR (300 MHz, DMSO- $\left.d_{6}\right)$ (Figure S3) $\delta$ $10.20(\mathrm{~s}, 1 \mathrm{H}, A r O H), 7.77(\mathrm{dd}, J=14.4,8.8 \mathrm{~Hz}, 4 \mathrm{H}, A r H), 7.00(\mathrm{dd}, J=42.2,8.9 \mathrm{~Hz}, 4 \mathrm{H}, A r H), 4.04(\mathrm{t}$, $\left.J=6.4 \mathrm{~Hz}, 2 \mathrm{H}, \mathrm{OCH}_{2}\right), 1.80-1.13\left(\mathrm{~m}, 22 \mathrm{H}, \mathrm{CH}_{2} \mathrm{CH}_{2}\right), 0.85\left(\mathrm{t}, J=6.5 \mathrm{~Hz}, 3 \mathrm{H}, \mathrm{CH}_{3}\right)$.

Compound 1b: Yield 58\%. ${ }^{1} \mathrm{H}$ NMR $\left(300 \mathrm{MHz}, \mathrm{CDCl}_{3}\right)$ (Figure S4) $\delta 8.00-7.84(\mathrm{~m}, 4 \mathrm{H}, \mathrm{ArH}), 7.00$ $(\mathrm{dd}, J=9.0,5.0 \mathrm{~Hz}, 4 \mathrm{H}, A r H), 4.04\left(\mathrm{t}, J=6.4 \mathrm{~Hz}, 2 \mathrm{H}, \mathrm{OCH}_{2}\right), 3.89\left(\mathrm{~s}, 3 \mathrm{H}, \mathrm{OCH}_{3}\right), 3.43(\mathrm{t}, J=6.8 \mathrm{~Hz}, 2 \mathrm{H}$, $\mathrm{CH}_{2} \mathrm{Br}$ ), 2.00-1.45 (m, 8H, $\left.\mathrm{CH}_{2} \mathrm{CH}_{2}\right)$. Compound 2b: Yield 83\%. ${ }^{1} \mathrm{H}$ NMR (300 MHz, $\mathrm{CDCl}_{3}$ ) (Figure S5) $\delta 7.88(\mathrm{~d}, J=9.0 \mathrm{~Hz}, 4 \mathrm{H}, A r H), 6.98(\mathrm{dd}, J=9.0,1.1 \mathrm{~Hz}, 4 \mathrm{H}, A r H), 4.03\left(\mathrm{td}, J=6.5,1.9 \mathrm{~Hz}, 4 \mathrm{H}, \mathrm{OCH}_{2}\right)$, $3.43\left(\mathrm{t}, J=6.8 \mathrm{~Hz}, 2 \mathrm{H}, \mathrm{CH}_{2} \mathrm{Br}\right), 1.99-1.35\left(\mathrm{~m}, 16 \mathrm{H}, \mathrm{CH}_{2} \mathrm{CH}_{2}\right), 0.92\left(\mathrm{t}, J=7.0 \mathrm{~Hz}, 3 \mathrm{H}, \mathrm{CH}_{3}\right)$. Compound 3b: Yield 61\%. ${ }^{1} \mathrm{H}$ NMR (300 MHz, $\left.\mathrm{CDCl}_{3}\right)$ (Figure S6) $\delta 7.97-7.79(\mathrm{~m}, 4 \mathrm{H}, \mathrm{ArH}), 6.96(\mathrm{dd}, J=11.7$, $8.9 \mathrm{~Hz}, 4 \mathrm{H}, \mathrm{ArH}), 4.03\left(\mathrm{dd}, J=7.9,5.2 \mathrm{~Hz}, 3 \mathrm{H}, \mathrm{OCH}_{2}\right), 3.42\left(\mathrm{q}, J=6.6 \mathrm{~Hz}, 3 \mathrm{H}, \mathrm{CH}_{2} \mathrm{Br}\right), 2.00-1.13(\mathrm{~m}$, $\left.30 \mathrm{H}, \mathrm{CH}_{2} \mathrm{CH}_{2}\right), 0.88\left(\mathrm{t}, J=6.7 \mathrm{~Hz}, 3 \mathrm{H}, \mathrm{CH}_{3}\right)$.

Compound 1c: Yield 89\%. ${ }^{1} \mathrm{H}$ NMR (300 MHz, $\mathrm{CDCl}_{3}$ ) (Figure S7) $87.98-7.73(\mathrm{~m}, 12 \mathrm{H}, \mathrm{ArH}), 7.27$ $(\mathrm{s}, 2 \mathrm{H}, A r H), 6.96(\mathrm{ddd}, J=10.6,8.0,5.0 \mathrm{~Hz}, 12 \mathrm{H}, A r H), 4.13-3.94\left(\mathrm{~m}, 12 \mathrm{H}, \mathrm{OCH}_{2}\right), 3.88(\mathrm{t}, J=4.2 \mathrm{~Hz}$, $\left.12 \mathrm{H}, \mathrm{OCH}_{3}\right), 1.97-1.43\left(\mathrm{~m}, 25 \mathrm{H}, \mathrm{CH}_{2} \mathrm{CH}_{2}\right)$. Compound 2c: Yield $83 \% .{ }^{1} \mathrm{H} \mathrm{NMR}\left(300 \mathrm{MHz}, \mathrm{CDCl}_{3}\right)$ (Figure S8) $\delta 7.89(\mathrm{dd}, J=8.9,1.6 \mathrm{~Hz}, 12 \mathrm{H}, A r H), 7.27(\mathrm{~s}, 2 \mathrm{H}, A r H), 6.97(\mathrm{dd}, J=9.0,3.1 \mathrm{~Hz}, 12 \mathrm{H}, A r H)$, $4.02\left(\mathrm{td}, J=6.3,3.4 \mathrm{~Hz}, 17 \mathrm{H}, \mathrm{OCH}_{2}\right), 3.89\left(\mathrm{~s}, 3 \mathrm{H}, \mathrm{OCH}_{3}\right), 1.82-1.35\left(\mathrm{~m}, 47 \mathrm{H}, \mathrm{CH}_{2} \mathrm{CH}_{2}\right), 0.91(\mathrm{t}, J=6.8 \mathrm{~Hz}$, 9H, $\left.\mathrm{CH}_{3}\right)$. Compound 3c: Yield 84\%. ${ }^{1} \mathrm{H}$ NMR $\left(300 \mathrm{MHz}, \mathrm{CDCl}_{3}\right)$ (Figure S9) $\delta 7.99-7.75(\mathrm{~m}, 12 \mathrm{H}$, $A r H), 7.27(\mathrm{~s}, 2 \mathrm{H}, A r H), 7.03-6.90(\mathrm{~m}, 12 \mathrm{H}, A r H), 4.02\left(\mathrm{dd}, J=11.3,6.5 \mathrm{~Hz}, 17 \mathrm{H}, \mathrm{OCH}_{2}\right), 3.89(\mathrm{~s}, 3 \mathrm{H}$, $\left.\mathrm{OCH}_{3}\right), 2.01-1.15\left(\mathrm{~m}, 90 \mathrm{H}, \mathrm{CH}_{2} \mathrm{CH}_{2}\right), 0.88\left(\mathrm{t}, J=6.6 \mathrm{~Hz}, 9 \mathrm{H}, \mathrm{CH}_{3}\right)$.

Compound 1d: Yield 80\%. ${ }^{1} \mathrm{H}$ NMR $\left(300 \mathrm{MHz}, \mathrm{CDCl}_{3}\right)$ (Figure S10) $\delta 7.84(\mathrm{ddd}, J=12.0,6.3,3.6$ $\mathrm{Hz}, 12 \mathrm{H}, A r H), 7.32(\mathrm{~s}, 2 \mathrm{H}, A r H), 6.96(\mathrm{ddd}, J=10.5,7.8,4.2 \mathrm{~Hz}, 12 \mathrm{H}, A r H), 4.02(\mathrm{dq}, J=13.3,6.4 \mathrm{~Hz}$, 
12H, $\left.\mathrm{OCH}_{2}\right), 3.86\left(\mathrm{~s}, 9 \mathrm{H}, \mathrm{OCH}_{3}\right), 1.96-1.43\left(\mathrm{~m}, 26 \mathrm{H}, \mathrm{CH}_{2} \mathrm{CH}_{2}\right)$. Compound 2d: Yield 85\%. ${ }^{1} \mathrm{H} \mathrm{NMR}$ $\left(300 \mathrm{MHz}, \mathrm{CDCl}_{3}\right)$ (Figure S11) $\delta 7.88(\mathrm{~d}, J=8.3 \mathrm{~Hz}, 12 \mathrm{H}, A r H), 7.33(\mathrm{~s}, 2 \mathrm{H}, A r H), 6.96(\mathrm{~d}, J=7.5 \mathrm{~Hz}$, $12 \mathrm{H}, \mathrm{ArH}), 4.02\left(\mathrm{dd}, J=13.5,6.8 \mathrm{~Hz}, 18 \mathrm{H}, \mathrm{OCH}_{2}\right), 2.00-1.23\left(\mathrm{~m}, 48 \mathrm{H}, \mathrm{CH}_{2} \mathrm{CH}_{2}\right), 0.91(\mathrm{t}, J=6.5 \mathrm{~Hz}, 9 \mathrm{H}$, $\mathrm{CH}_{3}$ ). Compound 3d: Yield 82\%. ${ }^{1} \mathrm{H}$ NMR $\left(300 \mathrm{MHz}, \mathrm{CDCl}_{3}\right)$ (Figure S12) $\delta 7.85(\mathrm{t}, J=7.0 \mathrm{~Hz}, 12 \mathrm{H}$, ArH), $7.31(\mathrm{~s}, 2 \mathrm{H}, A r H), 6.98(\mathrm{dd}, J=12.0,4.4 \mathrm{~Hz}, 12 \mathrm{H}, \mathrm{ArH}), 4.14-3.87\left(\mathrm{~m}, 17 \mathrm{H}, \mathrm{OCH}_{2}\right), 1.97-1.17(\mathrm{~m}$, $\left.90 \mathrm{H}, \mathrm{CH}_{2} \mathrm{CH}_{2}\right), 0.88\left(\mathrm{t}, J=6.5 \mathrm{~Hz}, 10 \mathrm{H}, \mathrm{CH}_{3}\right)$.

Synthesis of compounds $1 \mathbf{e}, \mathbf{2 e}$ and $\mathbf{3 e}$ is described further down. Compound $1 \mathbf{d}(2.10 \mathrm{~g}, 1.9 \mathrm{mmol})$ was dissolved in dry dichloromethane $(30 \mathrm{~mL})$. Thionyl chloride $(5 \mathrm{~mL})$ was added along with few drops of dry DMF. The reaction mixture was stirred at room temperature for $12 \mathrm{~h}$. Then, the stirring was stopped and the solvents were evaporated under vacuum. The crude product was obtained as a yellow solid and was taken to the next step without further purification. It was dissolved in dry dichloromethane $(30 \mathrm{~mL})$ and the solution was added drop-wise to an ice-cold flask containing ethylene diamine $(10 \mathrm{~mL})$. The reaction mixture was stirred in the same ice bath for another $3-4 \mathrm{~h}$ and then at room temperature for $12 \mathrm{~h}$. The reaction mixture was diluted with dichloromethane $(60 \mathrm{~mL})$ and washed with water, aqueous $\mathrm{NaHCO}_{3}$, and brine. The organic layer was dried over $\mathrm{Na}_{2} \mathrm{SO}_{4}$ and the solvent was evaporated to get the crude product, which was then added to ethanol $(60 \mathrm{~mL})$ and kept in the refrigerator for $2 \mathrm{~h}$. The precipitate was filtered under vacuum and dried to get the crude product as a yellow solid. It was taken to the next step without further purification. The compounds 2e and 3e were synthesized via the similar procedures. Compound 1e: Yield $73 \% .{ }^{1} \mathrm{H}$ NMR $(300 \mathrm{MHz}$, DMSO- $d_{6}$ ) (Figure S13) $\delta 8.33\left(\mathrm{~d}, J=7.5 \mathrm{~Hz}, 1 \mathrm{H}, N H_{2}\right), 7.77(\mathrm{dd}, J=18.0,10.2 \mathrm{~Hz}, 12 \mathrm{H}, A r H), 7.16(\mathrm{~s}$, $2 \mathrm{H}, A r H), 7.13-6.90(\mathrm{~m}, 12 \mathrm{H}, A r H), 4.07-3.85\left(\mathrm{~m}, 12 \mathrm{H}, \mathrm{OCH}_{2}\right), 3.83\left(\mathrm{~s}, 9 \mathrm{H}, \mathrm{OCH}_{3}\right), 3.26(\mathrm{~d}, J=6.5 \mathrm{~Hz}$, $\left.2 \mathrm{H}, \mathrm{CH}_{2}\right), 2.68\left(\mathrm{t}, \mathrm{J}=6.4 \mathrm{~Hz}, 2 \mathrm{H}, \mathrm{CH}_{2}\right), 1.91-1.30\left(\mathrm{~m}, 25 \mathrm{H}, \mathrm{NH}, \mathrm{CH}_{2} \mathrm{CH}_{2}\right)$. Compound 2e: Yield 79\%. ${ }^{1} \mathrm{H}$ NMR (300 MHz, DMSO- $d_{6}$ ) (Figure S14) $\delta 8.38\left(\mathrm{~s}, 1 \mathrm{H}, N_{2}\right), 7.80(\mathrm{dd}, J=13.4,8.3 \mathrm{~Hz}, 12 \mathrm{H}, A r H)$, $7.16(\mathrm{~s}, 2 \mathrm{H}, A r H), 7.07(\mathrm{dd}, J=14.1,8.1 \mathrm{~Hz}, 12 \mathrm{H}, A r H), 4.00\left(\mathrm{dd}, J=29.6,22.4 \mathrm{~Hz}, 17 \mathrm{H}, \mathrm{OCH}_{2}\right), 3.65(\mathrm{t}$, $\left.J=6.7 \mathrm{~Hz}, 3 \mathrm{H}, \mathrm{CH}_{2}\right), 2.73\left(\mathrm{~s}, 3 \mathrm{H}, \mathrm{CH}_{2}\right), 1.74-1.39\left(\mathrm{~m}, 55 \mathrm{H}, \mathrm{CH}_{2} \mathrm{CH}_{2}\right), 0.88\left(\mathrm{~s}, 9 \mathrm{H}, \mathrm{CH}_{3}\right)$. Compound 3e: Yield 81\%. ${ }^{1} \mathrm{H}$ NMR (300 MHz, $\mathrm{CDCl}_{3}$ ) (Figure S15) $\delta 8.04-7.70(\mathrm{~m}, 12 \mathrm{H}, \mathrm{ArH}), 6.97(\mathrm{dd}, J=11.5$, $4.8 \mathrm{~Hz}, 12 \mathrm{H}, A r H), 6.62(\mathrm{~s}, 2 \mathrm{H}, A r H), 4.11-3.85\left(\mathrm{~m}, 18 \mathrm{H}, \mathrm{OCH}_{2}\right), 3.33\left(\mathrm{~s}, 2 \mathrm{H}, \mathrm{CH}_{2}\right), 3.05\left(\mathrm{~s}, 3 \mathrm{H}, \mathrm{CH}_{2}\right)$, $1.80-1.41\left(\mathrm{~m}, 92 \mathrm{H}, \mathrm{CH}_{2} \mathrm{CH}_{2}\right), 0.88\left(\mathrm{t}, J=6.1 \mathrm{~Hz}, 10 \mathrm{H}, \mathrm{CH}_{3}\right)$.

Synthesis of compound $1 \mathbf{f}$ (PBI1), $\mathbf{2 f}$ (PBI2) and $\mathbf{3 f}$ (PBI3) is described further down. Compound 1e $(0.79 \mathrm{~g}, 0.66 \mathrm{mmol}), 3,4,9,10$-perylenetetracarboxylic dianhydride $(0.13 \mathrm{~g}, 0.33 \mathrm{mmol}), \mathrm{Zn}(\mathrm{OAc})_{2}$ $(0.07 \mathrm{~g}, 0.33 \mathrm{mmol})$, and imidazole $(12.00 \mathrm{~g})$ were taken together in a flask and were stirred at $130{ }^{\circ} \mathrm{C}$ for $24 \mathrm{~h}$ under an argon atmosphere. The reaction mixture was cooled to room temperature and poured into methanol $(100 \mathrm{~mL})$. The precipitate was filtered and the solid was washed several times with methanol. The crude product was recrystallized from THF and dried under vacuum to get $0.26 \mathrm{~g}$ of a red solid. Compounds $\mathbf{2 f}$ (PBI2) and $\mathbf{3 f}$ (PBI3) were synthesized by the similar procedures. Compound 1f (PBI1), yield: $30 \% .{ }^{1} \mathrm{H}$ NMR (300 MHz, DMSO- $d_{6}$, Figure S16) $\delta 8.74(\mathrm{~d}, J=7.9 \mathrm{~Hz}, 4 \mathrm{H}, A r H), 8.47$ $(\mathrm{d}, J=8.0 \mathrm{~Hz}, 4 \mathrm{H}, A r H), 8.20(\mathrm{t}, J=5.9 \mathrm{~Hz}, 2 \mathrm{H}, N H), 7.83-7.61(\mathrm{~m}, 24 \mathrm{H}, A r H), 7.02-6.90(\mathrm{~m}, 28 \mathrm{H}, A r H)$, $4.29\left(\mathrm{t}, J=5.5 \mathrm{~Hz}, 4 \mathrm{H}, \mathrm{CH}_{2}\right), 4.01-3.86\left(\mathrm{~m}, 24 \mathrm{H}, \mathrm{OCH}_{2}\right), 3.82\left(\mathrm{~d}, J=1.8 \mathrm{~Hz}, 18 \mathrm{H}, \mathrm{OCH}_{3}\right), 3.66(\mathrm{~d}, J=7.2$ $\left.\mathrm{Hz}, 4 \mathrm{H}, \mathrm{CH}_{2}\right), 1.78-1.35\left(\mathrm{~m}, 48 \mathrm{H}, \mathrm{CH}_{2} \mathrm{CH}_{2}\right)$. Matrix-assisted laser desorption ionization time-of-flight mass spectrometry (MALDI-TOF-MS), $\mathrm{m} / \mathrm{z}\left(+\mathrm{Na}^{+}\right)$: calculated for $\mathrm{C}_{156} \mathrm{H}_{160} \mathrm{~N}_{24} \mathrm{O}_{16}\left(+\mathrm{Na}^{+}\right), 2664.18$; found, 2664.28. Compound 2f (PBI2), yield 33\%. ${ }^{1} \mathrm{H}$ NMR (300 MHz, $\mathrm{CDCl}_{3}$, Figure S17) $\delta 8.55$ (d, $J=8.0 \mathrm{~Hz}, 4 \mathrm{H}, A r H), 8.39(\mathrm{~d}, J=8.1 \mathrm{~Hz}, 4 \mathrm{H}, A r H), 7.89-7.66(\mathrm{~m}, 24 \mathrm{H}, \operatorname{ArH}), 7.02(\mathrm{~s}, 4 \mathrm{H}, A r H), 6.99$ $(\mathrm{s}, 2 \mathrm{H}, \mathrm{NH}), 6.91(\mathrm{ddd}, J=17.9,10.7,6.2 \mathrm{~Hz}, 25 \mathrm{H}, \mathrm{ArH}), 4.51\left(\mathrm{~s}, 4 \mathrm{H}, \mathrm{CH}_{2}\right), 4.14-3.90\left(\mathrm{~m}, 36 \mathrm{H}, \mathrm{OCH}_{2}\right)$, $3.87\left(\mathrm{~s}, 5 \mathrm{H}, \mathrm{CH}_{2}\right), 1.96-1.29\left(\mathrm{~m}, 140 \mathrm{H}, \mathrm{CH}_{2} \mathrm{CH}_{2}\right), 0.91\left(\mathrm{t}, J=6.9 \mathrm{~Hz}, 17 \mathrm{H}, \mathrm{CH}_{3}\right)$. MALDI-TOF-MS, m/z $\left(+\mathrm{Na}^{+}\right)$: calculated for $\mathrm{C}_{186} \mathrm{H}_{220} \mathrm{~N}_{16} \mathrm{O}_{24}\left(+\mathrm{Na}^{+}\right)$, 3084.30; Found, 3085.71. Compound 3f (PBI3): Yield $34 \% .{ }^{1} \mathrm{H}$ NMR (300 MHz, CDCl 3 , Figure S18) $\delta 8.55(\mathrm{~s}, 4 \mathrm{H}, A r H), 8.43(\mathrm{~s}, 4 \mathrm{H}, \operatorname{ArH}), 7.93-7.63(\mathrm{~m}, 24 \mathrm{H}$, $\operatorname{ArH}), 7.02(\mathrm{~s}, 4 \mathrm{H}, \mathrm{ArH}), 6.88(\mathrm{~d}, J=16.6 \mathrm{~Hz}, 26 \mathrm{H}, \mathrm{ArH}, \mathrm{NH}), 4.51\left(\mathrm{~s}, 4 \mathrm{H}, \mathrm{CH}_{2}\right), 4.19-3.79\left(\mathrm{~m}, 36 \mathrm{H}, \mathrm{OCH}_{2}\right)$, $3.40\left(\mathrm{~s}, 5 \mathrm{H}, \mathrm{CH}_{2}\right), 1.79-1.15\left(\mathrm{~m}, 176 \mathrm{H}, \mathrm{CH}_{2} \mathrm{CH}_{2}\right), 0.88\left(\mathrm{~s}, 22 \mathrm{H}, \mathrm{CH}_{3}\right)$. MALDI-TOF-MS, m/z (+Na $\left.{ }^{+}\right)$: calculated for $\mathrm{C}_{222} \mathrm{H}_{292} \mathrm{~N}_{16} \mathrm{O}_{24}\left(+\mathrm{Na}^{+}\right)$, 3589.21; found, 3590.21 . 


\subsection{Preparation of Solutions of PBI Derivatives}

Due to the poor solubility of PBI derivatives, we chose DMF (hydrogen bond breaking) and DCE (without hydrogen bond breaking) as solvents for the comparative study. The PBI derivatives were dissolved in DMF and DCE by heating and formed a solution of $1.0 \times 10^{-5} \mathrm{~mol} \cdot \mathrm{L}^{-1}$, respectively.

\subsection{Fabrication of Nanostructures}

One milliliter of a DMF solution of the compounds PBI1, PBI2, and PBI3 $\left(1.0 \times 10^{-5} \mathrm{~mol} \cdot \mathrm{L}^{-1}\right)$ before and after irradiation with $365 \mathrm{~nm}$ and $436 \mathrm{~nm}$ wavelength light for $30 \mathrm{~min}$, respectively, was injected into $5 \mathrm{~mL}$ of methanol in a test tube followed by $1 \mathrm{~h}$ of aging, the assemblies thus formed accordingly. The assemblies can be transferred and casted onto a copper grid by pipetting. It is worth mentioning that the morphological change of the nanostructures in the dark can take place in the solution dispersion, but is restricted in solid state, i.e., when casting on substrates such as a copper grid, the morphologies can remain for more than 3 months.

\subsection{Characterization}

The ${ }^{1} \mathrm{H}$ NMR spectra were recorded on a Bruker $300 \mathrm{MHz}$ spectrometer (Bruker, Billerica, MA, USA) and were referenced internally to TMS as an internal standard at $0.00 \mathrm{ppm}$. Ultraviolet visible (UV-VIS) absorption spectra of the samples were recorded on a Shimadzu UV-2600 spectrophotometer (Kyoto, Japan) at room temperature. Matrix-assisted laser desorption/ionization time-of-flight mass spectrometry (MALDI-TOF-MS) measurement was performed using a Bruker UltrafleXtreme (MALDI-TOF/TOF) mass spectrometer (Bruker, Billerica, MA, USA) equipped with a $355 \mathrm{~nm}$ Nd:YAG laser. Both matrix (2-[(2E)-3-(4-tert-butylphenyl)-2-methyl-prop-2-enylidene] malononitrile (DCTB)) (at a concentration of ca. $20 \mathrm{mg} \mathrm{mL}^{-1}$ ) and all samples were dissolved in chloroform (at a concentration of ca. $10 \mathrm{mg} \cdot \mathrm{mL}^{-1}$ ). The light intensities of $365 \mathrm{~nm}$ and $436 \mathrm{~nm}$ were about $2.0 \mathrm{~mW} \mathrm{~cm}{ }^{-2}$ and $0.88 \mathrm{~mW}$ $\mathrm{cm}^{-2}$, respectively. The light intensity was measured by using a UV radiometer, UV-420 (photoelectric instrument factory of Beijing Normal University). TEM was recorded on HITACHI HT7700 employing an accelerating voltage of $120 \mathrm{kV}$.

\section{Results and Discussion}

\subsection{Synthesis and Characterization of Azo-Functionalized PBIs 1-3}

The Azo-functionalized PBI derivatives (PBIs 1-3) with different alkyl chain lengths were synthesized by imidization of 3,4,9,10-perylene tetracarboxylic dianhydride with corresponding amines as shown in Scheme 1. The structures of PBIs 1-3 were characterized by ${ }^{1} \mathrm{H}$ NMR and MALDI-TOF-MS spectra. We chose DMSO- $d_{6}$ as solvent for PBI1 and $\mathrm{CDCl}_{3}$ for PBI2 and PBI3 according to their different solubility for NMR measurement. As shown in Figure 1, there exist multiplet peaks at 8.36-8.78 ppm (perylene-H), multipet peaks at 7.65-7.86 ppm and 6.76-7.06 ppm (Ar-H and Azo-H), multiplet peaks at 3.85-4.15 ppm $\left(-\mathrm{OCH}_{2}-\right), 4.25-4.60 \mathrm{ppm}\left(-\mathrm{N}-\mathrm{CH}_{2}-\right)$, and $1.10-1.90 \mathrm{ppm}$ $\left(-\mathrm{CH}_{2}-\mathrm{CH}_{2}-\right)$; triplet peaks at 8.15-8.25 ppm (-CONH-), multiplet peaks at 3.60-3.70 ppm $\left(-\mathrm{NH}-\mathrm{CH}_{2}-\right)$, and single peak at 3.80-3.83 ppm (-OCH $\left.{ }_{3}\right)$ of PBI1, multiplet peaks at 7.00-7.05 ppm (-CONH-) and 3.35-3.90 ppm (-NH-CH $\left.-\mathrm{CH}_{2}-\right)$, triplet peaks at 0.82-0.96 ppm $\left(-\mathrm{CH}_{2} \mathrm{CH}_{3}\right)$ of PBI2 and PBI3 with the ratio of the integrated areas of the peaks in accordance with the proton number of the expected compounds, respectively. Meanwhile, the MALDI-TOF-MS spectra of PBI1, PBI2, and PBI3 (Figure 2) demonstrated the corresponding experimental peaks $m / z$ values with sodium ion at $2664.28,3085.71$, and $3590.21 \mathrm{Da}$, respectively, which matched well with the theoretical calculating values $(2664.18,3084.30$, and 3589.21 Da). All these characteristic data confirmed the successful synthesis of Azo-functionalized PBI derivatives (PBIs 1-3). 


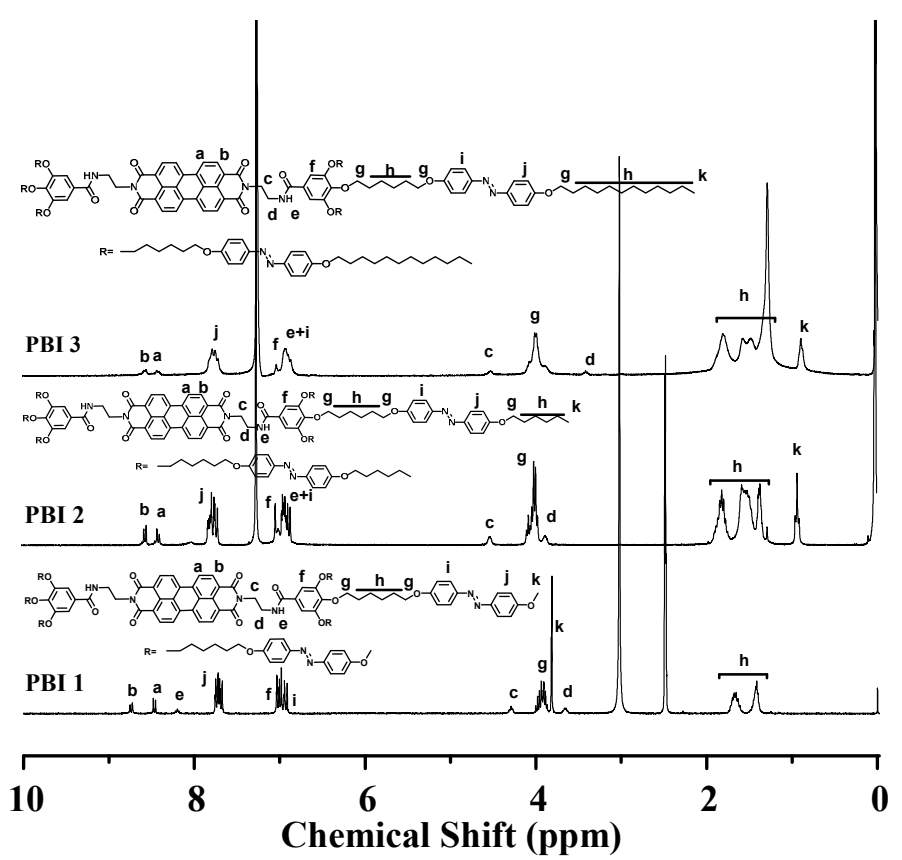

Figure 1. Proton nuclear magnetic resonance $\left({ }^{1} \mathrm{H}\right.$ NMR) spectra of PBI1 in DMSO- $d_{6}$, and PBI2 and PBI3 in $\mathrm{CDCl}_{3}$.

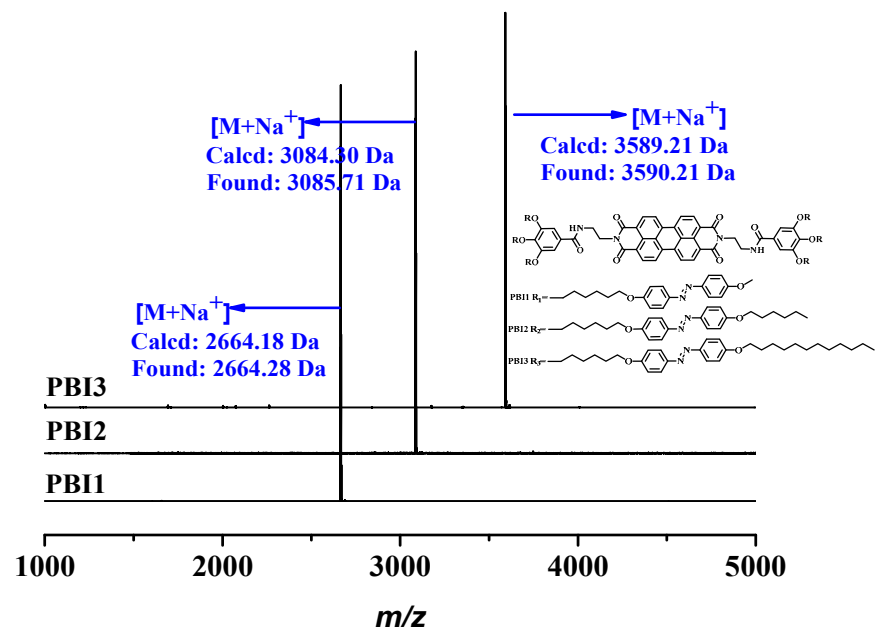

Figure 2. Matrix-assisted laser desorption ionization time-of-flight mass spectrometry (MALDI-TOF-MS) spectra of PBI1, PBI2, and PBI3.

\subsection{Photoisomerization Behaviors of PBIs 1-3 in the Solution}

The synergic interactions of $\pi$ - $\pi$-interaction of perylene and Azo groups, hydrogen bond, and the van der Waals force enforces the PBI derivatives to form supramolecular nanostructures [29]. As shown in Figure 3, the absorption peaks at $360 \mathrm{~nm}$ and $458 \mathrm{~nm}$ are, respectively, related to the $\pi-\pi^{*}$ transition of Azo trans-configuration and $\mathrm{n}-\pi^{*}$ transition of Azo cis-configuration [39], and the absorption peaks at $490 \mathrm{~nm}$ and $520 \mathrm{~nm}$ represent absorbance of PBI core [29]. In DMF, the UV-VIS absorption intensities at $360 \mathrm{~nm}$ of all the Azo-functionalized PBI derivatives (PBIs 1-3) decreased significantly, along with gradual increase of UV-VIS absorption at $458 \mathrm{~nm}$, indicating the trans-to-cis transformation of Azo units under $365 \mathrm{~nm}$ wavelength light irradiation. The trans-configuration of Azo groups in PBI structures were almost completely converted to cis-configuration and the photostationary state (PPS) time for PBIs 1-3 were $90 \mathrm{~s}$ (PBI1), $60 \mathrm{~s}$ (PBI2), and $90 \mathrm{~s}$ (PBI3), respectively. Subsequently, the cis-to-trans transformation of Azo units in PBIs was triggered by irradiating with $436 \mathrm{~nm}$ wavelength light. 
As presented in Figure $3 \mathrm{~b}, \mathrm{~d}, \mathrm{f}$, the absorption values at $360 \mathrm{~nm}\left(\pi-\pi^{*}\right.$ transition of trans-Azo $)$ of PBIs 1-3 all significantly increased along with the gradual decrease of absorption intensities at $458 \mathrm{~nm}\left(\mathrm{n}-\pi^{*}\right.$ transition of cis-Azo), indicating the successful cis-to-trans photoisomerization. The PPS times for PBIs 1-3 were $240 \mathrm{~s}, 300 \mathrm{~s}$, and $180 \mathrm{~s}$, respectively.
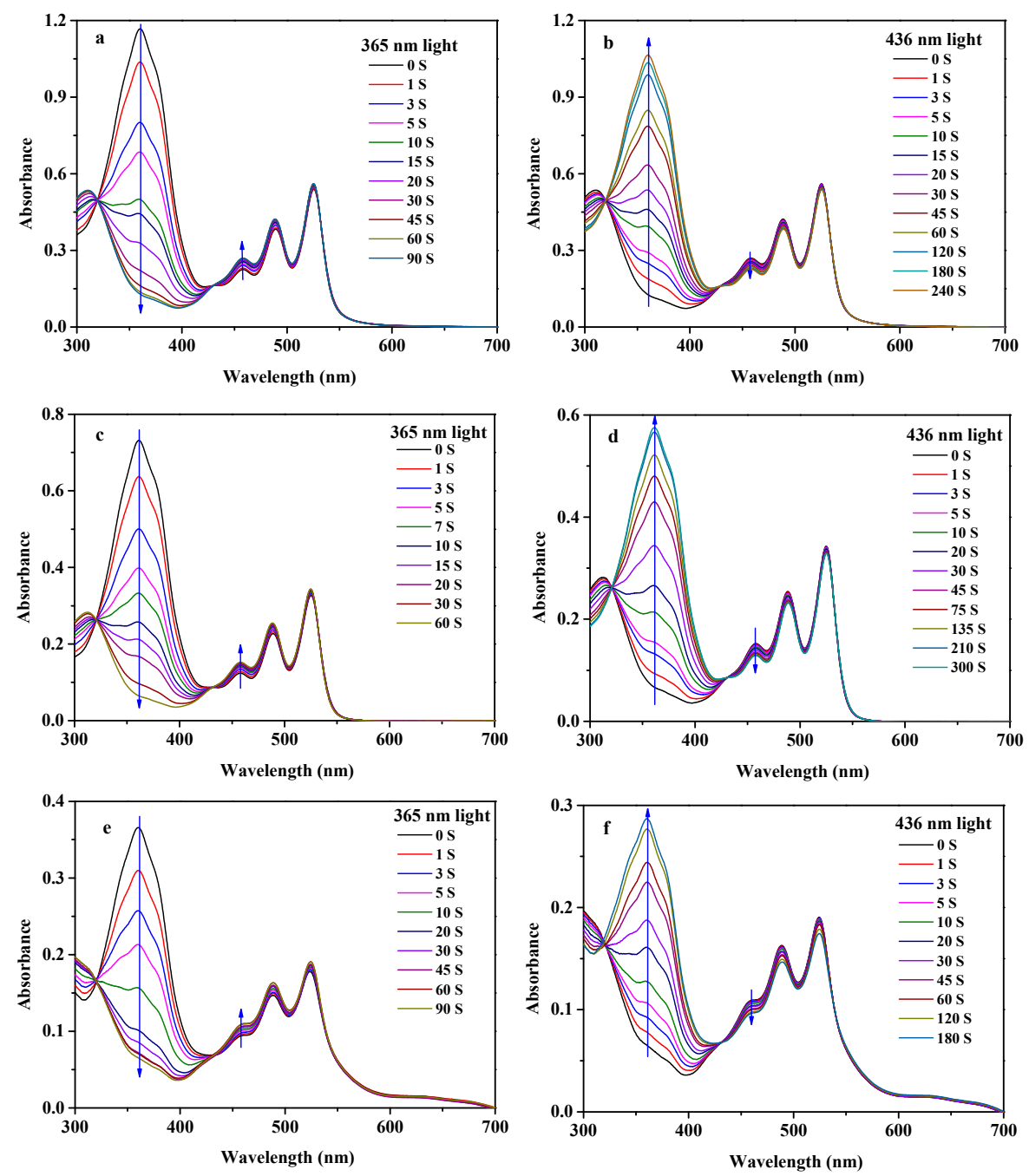

Figure 3. UV-VIS spectra of PBI1 $(\mathbf{a}, \mathbf{b})$, PBI2 $(\mathbf{c}, \mathbf{d})$, and PBI3 $(\mathbf{e}, \mathbf{f})$ assemblies in DMF by alternating irradiation with $365 \mathrm{~nm}$ and $436 \mathrm{~nm}$ wavelength light.

The reversibility of the photoisomerization of PBIs 1-3 was verified by alternating irradiation with $365 \mathrm{~nm}$ and $436 \mathrm{~nm}$ wavelength light for $3 \mathrm{~min}$ and $5 \mathrm{~min}$, respectively. As seen in Figure 4, the reversible changes of UV-VIS absorption intensities were tested in cases of PBIs 1-3, which could proceed more than ten times. Meanwhile, almost no obvious difference of photoisomerization behavior was detected among PBIs 1-3 with different alkyl chain lengths in Azo units. The good fatigue resistance and optical switch properties provided us a basis for the subsequent morphology regulation of PBI aggregates. 

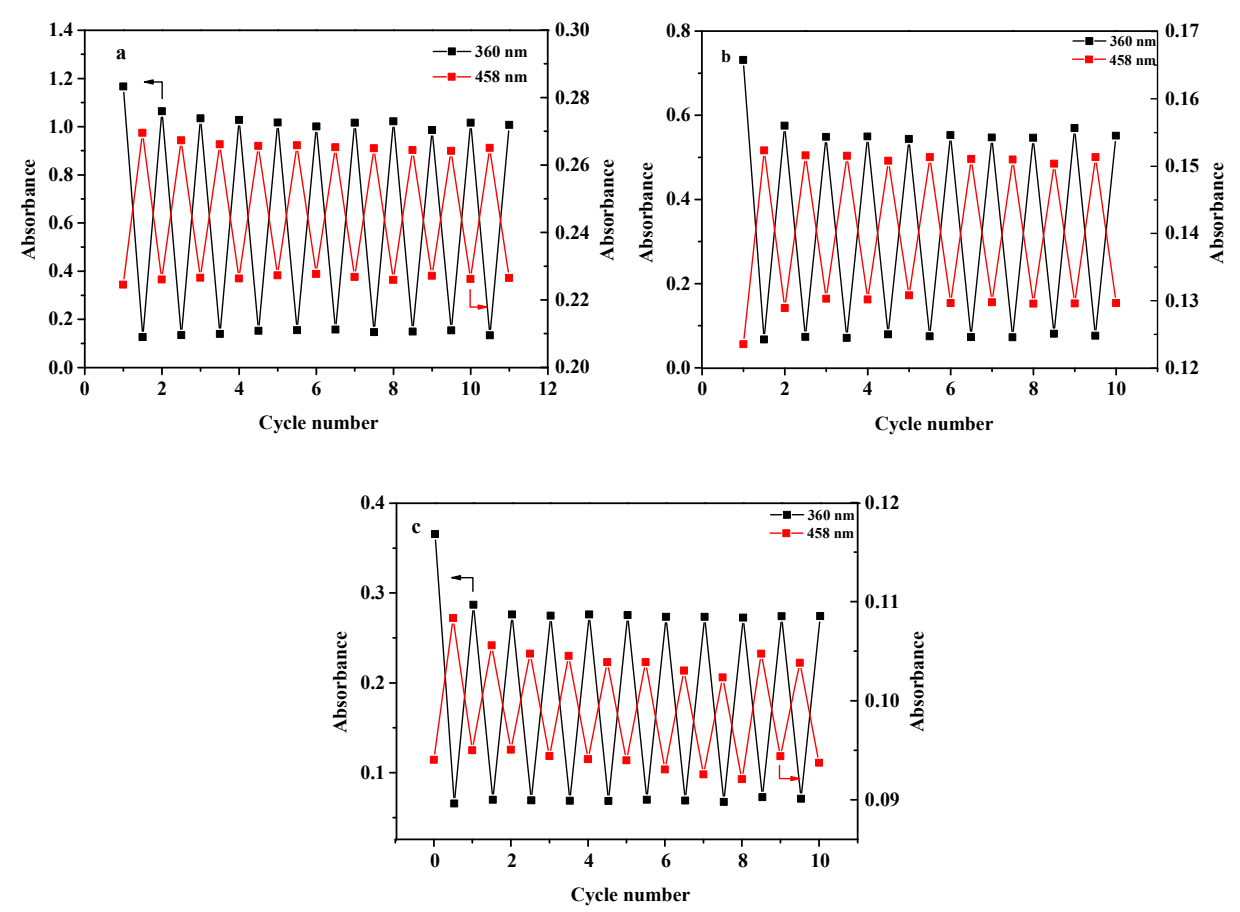

Figure 4. Reversible photoisomerization of PBI1 (a), PBI2 (b), and PBI3 (c) aggregates in DMF upon alternating irradiation with $365 \mathrm{~nm}$ and $436 \mathrm{~nm}$ wavelength light at $25{ }^{\circ} \mathrm{C}$. The irradiation time: 3 and $5 \mathrm{~min}$ for $365 \mathrm{~nm}$ and $436 \mathrm{~nm}$ wavelength light. The absorption value change for trans- and cis-configuration was taken from $360 \mathrm{~nm}$ (black) and $458 \mathrm{~nm}$ (red), respectively.

Considering the different hydrogen bond $(\mathrm{N}-\mathrm{H} \cdots \mathrm{O}=\mathrm{C})$ ability between $\mathrm{PBI}$ and the solvent, the similar photoisomerization behaviors of PBIs 1-3 were investigated in DCE. As shown in Figure 5, the change tendency of the absorption intensities at $360 \mathrm{~nm}$ and $458 \mathrm{~nm}$ positions were similar to those in DMF. Interestingly, it was notable that the photoisomerization ability of PBIs 1-3 became weaker with the increase of alkyl chain length. It means that the photoisomerization ability followed the order of PBI1 > PBI2 > PBI3. The possible reason may be that the longer the alkyl chain, the stronger van der Waals force between PBI units, which impedes the photoisomerization of Azo units. By comparing the UV-VIS absorption spectra of PBIs 1-3 in DMF and DCE, the photoisomerization ability of PBIs 1-3 in DCE was much weaker than that in DMF, especially for PBI2 and PB 3. The reason is that the hydrogen bond between DMF and PBI depresses the hydrogen bond interaction between PBI units [29]. Furthermore, the reversibility of the photoisomerization of PBIs 1-3 also became weaker with the increase of alkyl chain length as demonstrated in Figure 6. In the cases of PBI2 and PBI3, some aggregates precipitated from the solvent after several photoisomerization cycles due to the much stronger interactions between PBI units, which resulted from the increase of van der Waals force with the longer alkyl chain length.
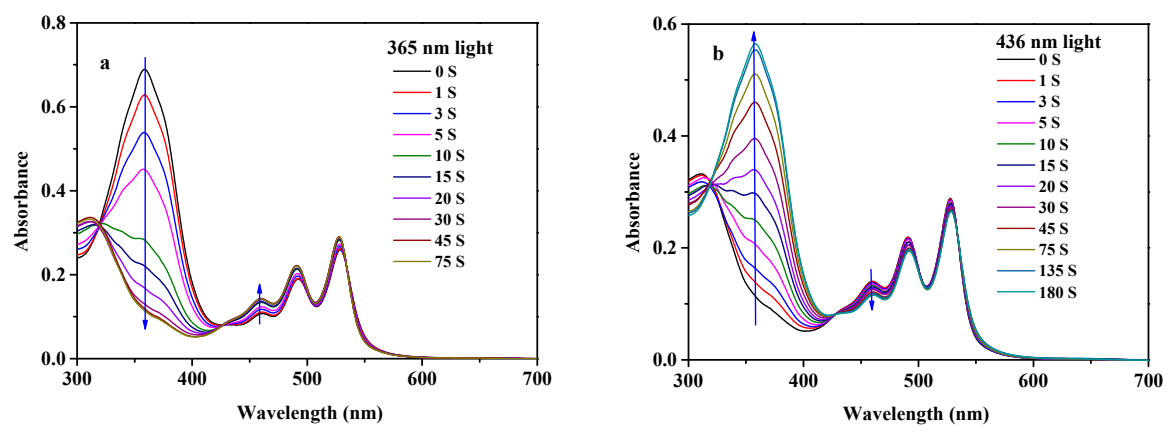

Figure 5. Cont. 

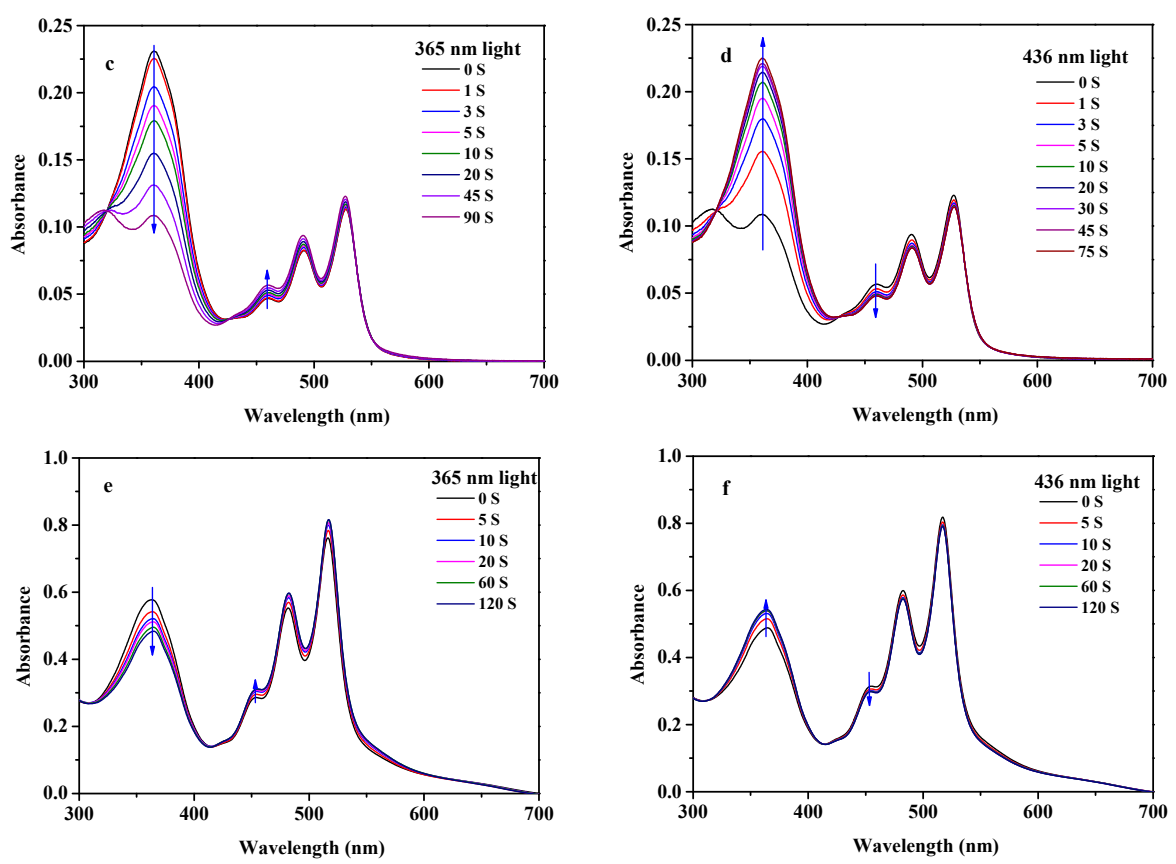

Figure 5. UV-Vis spectra of PBI1 (a,b), PBI2 (c,d), and PBI3 (e,f) assemblies in DCE by alternating irradiation with $365 \mathrm{~nm}$ and $436 \mathrm{~nm}$ wavelength light.
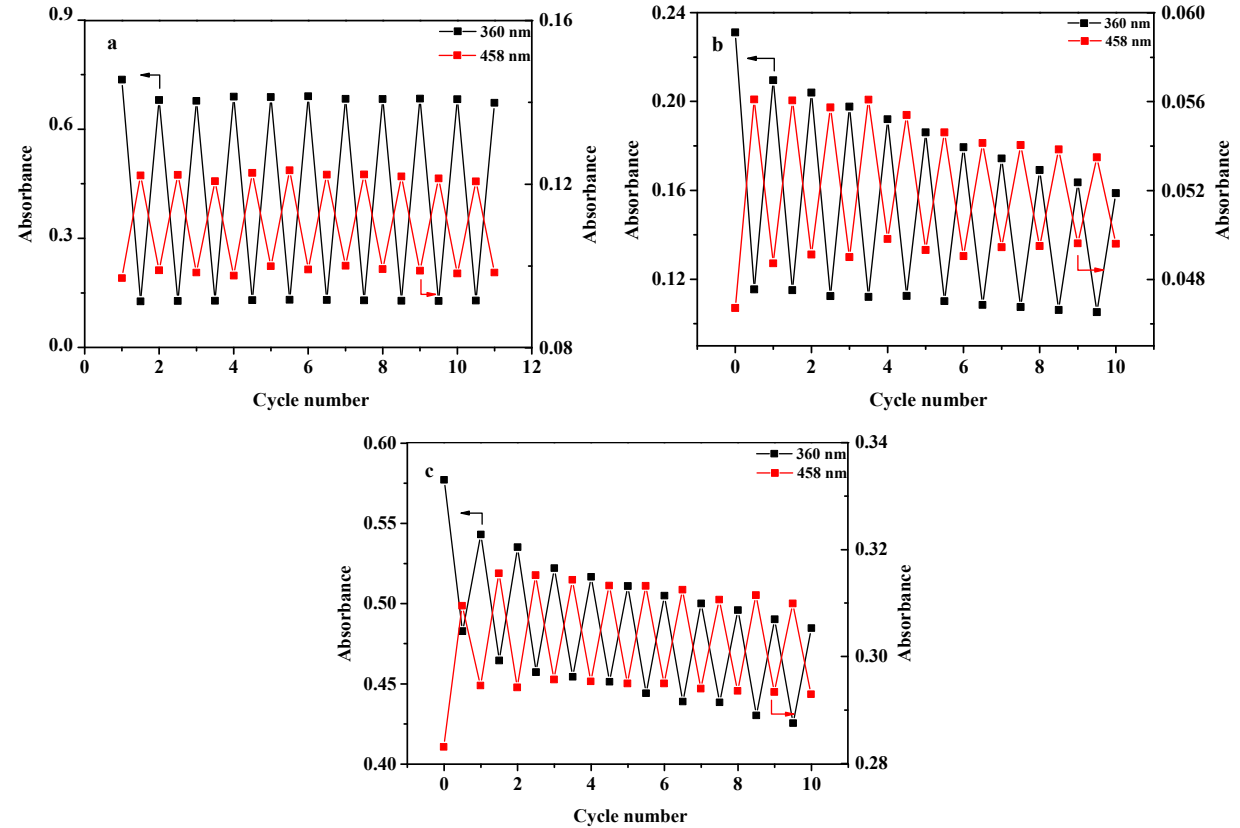

Figure 6. Reversible photoisomerization of PBI1 (a), PBI2 (b), and PBI3 (c) aggregates in DCE upon alternating irradiation with $365 \mathrm{~nm}$ and $436 \mathrm{~nm}$ wavelength light at $25{ }^{\circ} \mathrm{C}$. The irradiation time: 3 and $5 \mathrm{~min}$ for $365 \mathrm{~nm}$ and $436 \mathrm{~nm}$ wavelength light. The absorption value change for trans- and cis-configuration was taken from $360 \mathrm{~nm}$ (black) and $458 \mathrm{~nm}$ (red), respectively.

The concentration- and temperature-dependent UV-VIS spectra of PBIs 1-3 were further investigated and results are given in Figures S19 and S20. Figure S19 shows, the UV-VIS absorption intensities for Azo and PBI unit in PBIs1-3 all enhanced with the increase of concentration in both DMF and DCE. Interestingly, the relationship of UV-VIS absorption intensity and concentration is not linear (inserted images) for PBIs1-3, demonstrating there were aggregates that existed. Figure S20 shows that only UV-Vis absorption intensity of PBI3 in the DMF solution increased with temperature (from 30 to $90{ }^{\circ} \mathrm{C}$ ); however, the UV-VIS absorption intensities of DMF solutions of PBI1 and PBI2 and DCE 
solutions of PBIs 1-3 all increased with the decrease of temperature. Meanwhile, the slight red-shift of absorption peaks with a decrease in temperature were observed in the cases of DMF solutions of PBI1 and PBI2 and DCE solutions of PBIs 1-3. This phenomenon is unusual and the reason is indistinct, which is why it needs further study in the future.

To further investigate the difference of photoisomerization rates of PBIs 1-3 in DMF and DCE, we calculated the photoisomeriaztion rate constants of trans-to-cis $\left(K_{\mathrm{e}}\right)$ and cis-to-trans $\left(K_{\mathrm{h}}\right)$ of the Azo units. The $K_{\mathrm{e}}$ and $K_{\mathrm{h}}$ values are calculated by fitting the experimental data to the following equation [44,45]:

$$
\ln \left[\left(\mathrm{A}_{\infty}-\mathrm{A}_{0}\right) /\left(\mathrm{A}_{\infty}-\mathrm{A}_{\mathrm{t}}\right)\right]=K \mathrm{t}
$$

where $A_{\infty}, A_{0}$, and $A_{t}$ are absorbances at $360 \mathrm{~nm}$ at infinite time, time zero, and time $t$, respectively. Figure 7 indicates the first-order kinetic plots of the trans-to-cis and cis-to-trans photoisomerization of the PBIs 1-3 in DMF. The corresponding $K_{\mathrm{e}}$ and $K_{\mathrm{h}}$ values are listed in Table 1 . Obviously, their trans-cis photoisomerization behavior in DMF obeyed the first-order reaction. Under $365 \mathrm{~nm}$ wavelength light irradiation, the $K_{\mathrm{e}}$ values of PBI1, PBI2, and PBI3 are $0.0767 \mathrm{~s}^{-1}, 0.0955 \mathrm{~s}^{-1}$, and $0.0896 \mathrm{~s}^{-1}$, respectively. The photoisomerization rate of PBI2 is slightly faster, but the difference with that of PBI1 and PBI3 was small. Under $436 \mathrm{~nm}$ wavelength light irradiation, the $K_{\mathrm{h}}$ values of PBI1, PBI2, and PBI3 are 0.0257 $\mathrm{s}^{-1}, 0.0262 \mathrm{~s}^{-1}$, and $0.0269 \mathrm{~s}^{-1}$, respectively, which show almost no difference. In DCE, as shown in Figure 8, only PBI1 showed the first-order kinetic photoisomerization process. The $K_{\mathrm{e}}$ value is 0.1045 $\mathrm{s}^{-1}$ and the $K_{\mathrm{h}}$ value is $0.0320 \mathrm{~s}^{-1}$, which is close to that in DMF.
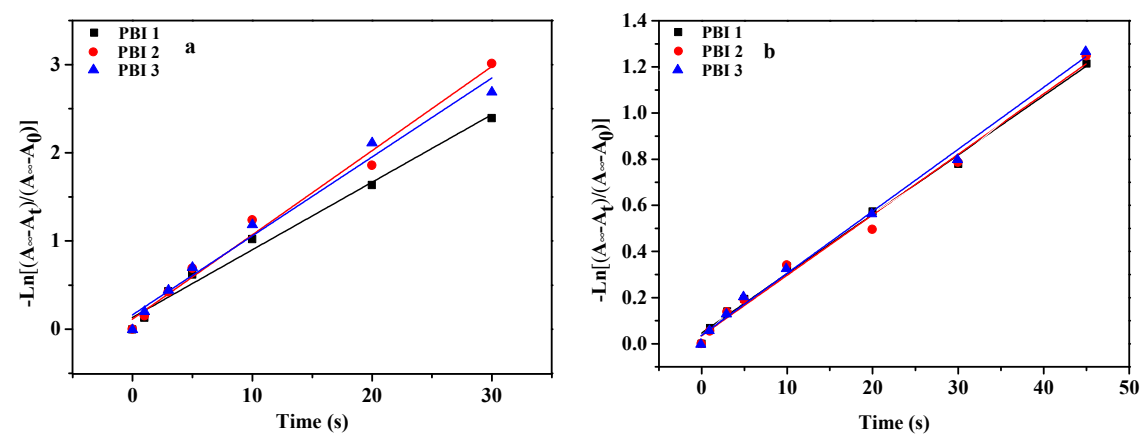

Figure 7. First-order kinetics for the photoisomerization of PBIs 1-3 by irradiation with $365 \mathrm{~nm}$ (a) and $436 \mathrm{~nm}(\mathbf{b})$ wavelength light in DMF.
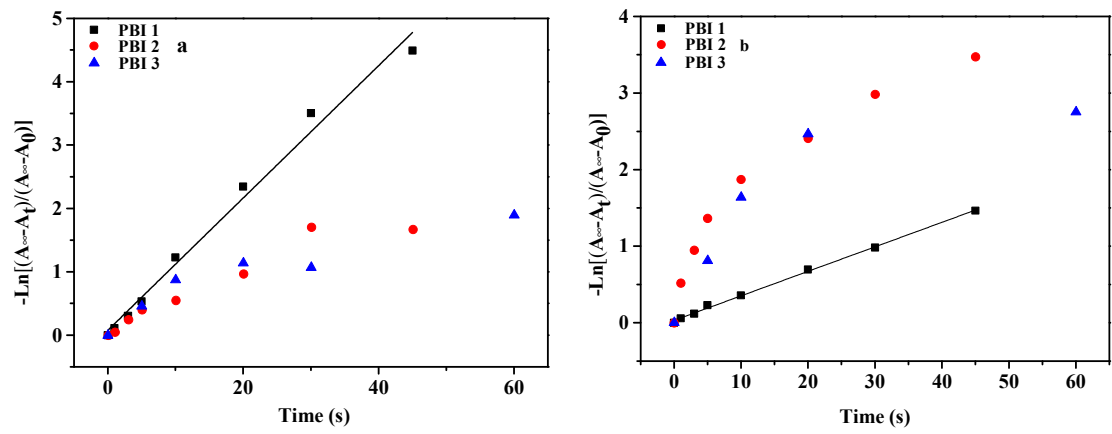

Figure 8. First-order kinetics for the photoisomerization of PBIs 1-3 by irradiation with $365 \mathrm{~nm}$ (a) and $436 \mathrm{~nm}(\mathbf{b})$ wavelength light in DCE.

Table 1. Photoisomerization rate of PBIs in DMF.

\begin{tabular}{ccc}
\hline Entry & $K_{\mathrm{e}} / \mathbf{s}^{-1}$ & $K_{\mathrm{h}} / \mathrm{s}^{-\mathbf{1}}$ \\
\hline PBI1 & 0.0767 & 0.0257 \\
PBI2 & 0.0955 & 0.0262 \\
PBI3 & 0.0896 & 0.0269 \\
\hline
\end{tabular}




\subsection{Morphology Photocontrol of PBIs 1-3 in DMF}

As compared in the photoisomerization behaviors in different solvents, PBIs 1-3 took the reversible photoisomerization in DMF, which provided a clue for the morphology control of the PBIs aggregates. Figure 9 presents the typical TEM images of PBIs 1-3 assemblies in DMF. PBI1 formed the well-defined long fibers with the width of $90 \pm 2 \mathrm{~nm}$ and several micrometers in length. The synergic interactions of $\pi-\pi$-interaction of perylene and Azo units and van der Waals force are contributed to the formation of fibers [29], but the hydrogen bond between PBI units was weakened by DMF. As the alkyl chain length increases, the van der Waals force increases and the alkyl chains may entangle with each other. PBI2 formed short fibers and PBI3 just formed fiber-like assemblies, respectively. Subsequently, the above aggregates were irradiated with $365 \mathrm{~nm}$ wavelength light for $30 \mathrm{~min}$ to ensure the complete transformation of trans- to cis-configuration of Azo groups. For PBI1, the morphology of assembly remained fibers but the width of them changed from $90 \pm 2 \mathrm{~nm}$ to $60 \pm 5 \mathrm{~nm}$. For PBI2, the length of fibers became shorter and their form a slender willow leaf-like structure. For PBI3, the morphology changed from fiber-like shape to nanoparticles. Subsequently, we irradiated these aggregates with 436 $\mathrm{nm}$ wavelength light for $30 \mathrm{~min}$ to ensure the Azo groups to transform from cis- to trans-configuration thoroughly. The morphology of PBIs 1-3 aggregates all showed the recovering tendency. For PBI1, the assembly remained fibers and the width of them increased to $70 \pm 3 \mathrm{~nm}$. For PBI2, the morphology retransformed to the fibers but with a much narrow width. For PBI3, the assembly returned to a fiber-like shape but with a much bigger size. It showed that the morphology of assembly can be regulated by reversible photoisomerization of Azo groups, especially for PBI2.

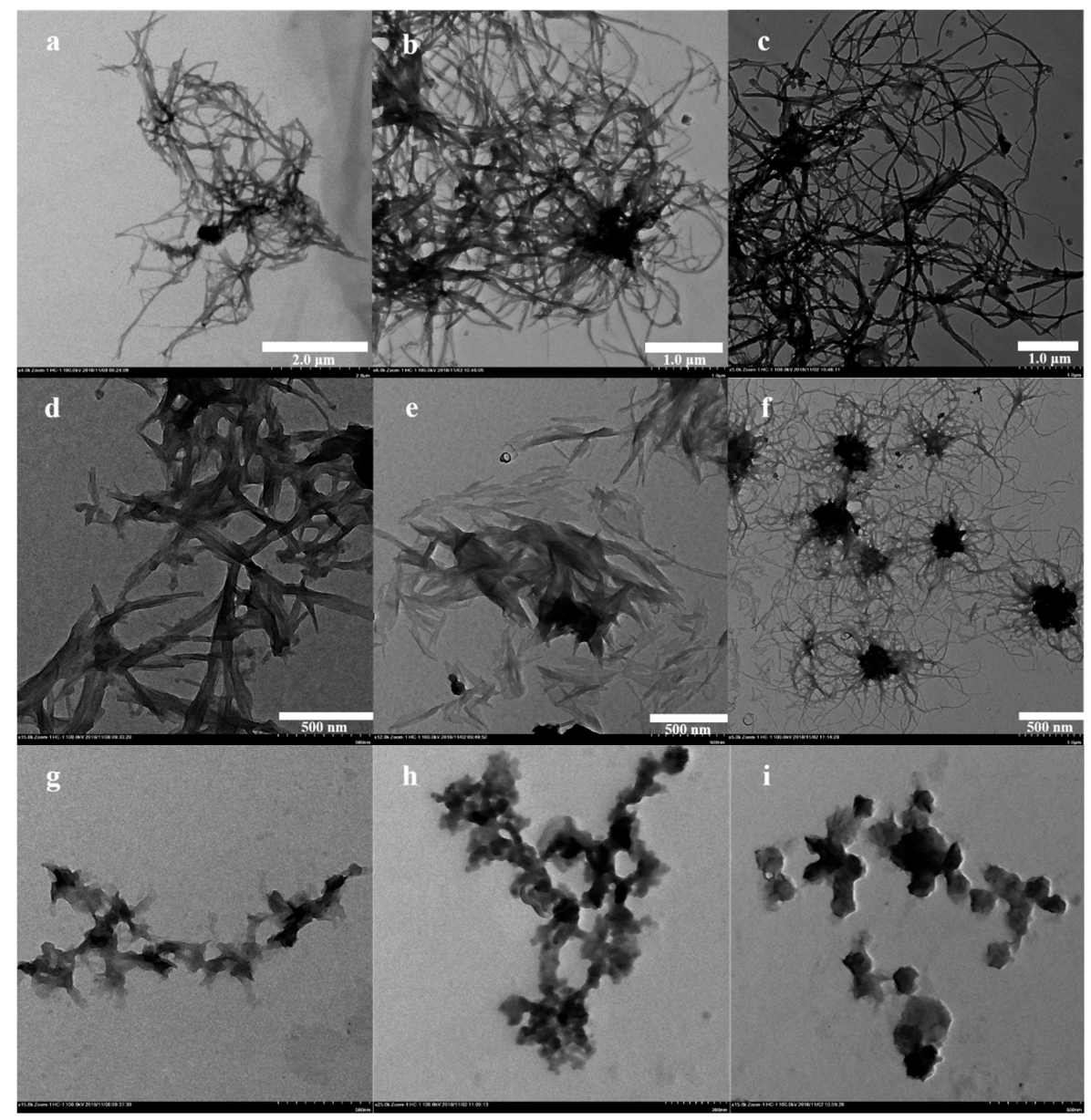

Figure 9. TEM images of PBI1 (a-c), PBI2 (d-f), and PBI3 (g-i) aggregates in DMF/ $\mathrm{CH}_{3} \mathrm{OH}$. From left to right: Before irradiation, irradiated with $365 \mathrm{~nm}$ wavelength light for $30 \mathrm{~min}$, irradiated with $436 \mathrm{~nm}$ wavelength light for $30 \mathrm{~min}$, respectively. 


\section{Conclusions}

In summary, we designed and synthesized three Azo-functionalized PBI derivatives with different alkyl chain lengths. They were able to assembly to supramolecular structures by the cooperation of $\pi-\pi$ stacking, hydrogen bond, and the van der Waals force. The Azo groups in PBIs 1-3 were able to take photoisomerization and the magnitude of intermolecular interaction force is the key factor for the photoisomerization process. The TEM test showed that the longer alkyl chain was not conducive to the formation of the fibers. In DMF, PBI1 and PBI2 with one and six carbon atom alkyl chains assembled to form the fibers, while PBI3 with 12 carbon atom alkyl chains could only form the fiber-like assembly. For perylene bisimide derivative PBI2 with a medium alkyl chain length, when Azo groups were in trans-configuration, the short fibers formed. By $365 \mathrm{~nm}$ ultraviolet light irradiation, the assembly transformed into a slender willow leaf-like structure due to the transformation of trans- to cis-configuration of Azo groups. When the solution was irradiated with $436 \mathrm{~nm}$ visible light, the Azo groups transformed from cis- to trans-configuration, which resulted in re-transformation to the fibers. By reversible trans-cis photoisomerization, the morphology of assembly can be regulated. The current results will provide a way for designing light-responsive PBI-based supramolecular polymers.

Supplementary Materials: The detailed synthesis of compounds a-d are available online at http://www.mdpi. com/2073-4360/11/7/1143/s1.

Author Contributions: W.L., X.C., T.M., and S.Z. performed the experiments, analyzed the data and wrote the manuscript. W.Z. and X.Z. designed the experimental plan and revised the manuscript.

Acknowledgments: The authors are grateful for the financial support from the National Nature Science Foundation of China (21574089), the Priority Academic Program Development (PAPD) of Jiangsu Higher Education Institutions, and the Program of Innovative Research Team of Soochow University.

Conflicts of Interest: The authors declare no conflict of interest.

\section{References}

1. Balakrishnan, K.; Datar, A.; Naddo, T.; Huang, J.; Oitker, R.; Yen, M.; Zhao, J.; Zang, L. Effect of side-chain substituents on self-assembly of perylene diimide molecules: Morphology control. J. Am. Chem. Soc. 2006, 128, 7390-7398. [CrossRef] [PubMed]

2. Zhang, X.; Chen, Z.; Würthner, F. Morphology control of fluorescent nanoaggregates by co-self-assembly of wedge- and dumbbell-shaped amphiphilic perylene bisimides. J. Am. Chem. Soc. 2007, 129, 4886-4887. [CrossRef] [PubMed]

3. Roeffaers, M.B.J.; Ameloot, R.; Baruah, M.; Uji-i, H.; Bulut, M.; De Cremer, G.; Müller, U.; Jacobs, P.A.; Hofkens, J.; Sels, B.F.; et al. Morphology of large zsm-5 crystals unraveled by fluorescence microscopy. J. Am. Chem. Soc. 2008, 130, 5763-5772. [CrossRef] [PubMed]

4. Kaiser, T.E.; Stepanenko, V.; Würthner, F. Fluorescent j-aggregates of core-substituted perylene bisimides: Studies on structure-property relationship, nucleation-elongation mechanism, and sergeants-and-soldiers principle. J. Am. Chem. Soc. 2009, 131, 6719-6732. [CrossRef] [PubMed]

5. Fukaminato, T.; Doi, T.; Tamaoki, N.; Okuno, K.; Ishibashi, Y.; Miyasaka, H.; Irie, M. Single-molecule fluorescence photoswitching of a diarylethene-perylenebisimide dyad: Non-destructive fluorescence readout. J. Am. Chem. Soc. 2011, 133, 4984-4990. [CrossRef] [PubMed]

6. Fennel, F.; Wolter, S.; Xie, Z.; Plötz, P.-A.; Kühn, O.; Würthner, F.; Lochbrunner, S. Biphasic self-assembly pathways and size-dependent photophysical properties of perylene bisimide dye aggregates. J. Am. Chem. Soc. 2013, 135, 18722-18725. [CrossRef] [PubMed]

7. Struijk, C.W.; Sieval, A.B.; Dakhorst, J.E.J.; van Dijk, M.; Kimkes, P.; Koehorst, R.B.M.; Donker, H.; Schaafsma, T.J.; Picken, S.J.; van de Craats, A.M.; et al. Liquid crystalline perylene diimides: Architecture and charge carrier mobilities. J. Am. Chem. Soc. 2000, 122, 11057-11066. [CrossRef]

8. Gregg, B.A.; Cormier, R.A. Doping molecular semiconductors: N-type doping of a liquid crystal perylene diimide. J. Am. Chem. Soc. 2001, 123, 7959-7960. [CrossRef]

9. Würthner, F. Perylene bisimide dyes as versatile building blocks for functional supramolecular architectures. Chem. Commun. 2004, 1564-1579. [CrossRef] 
10. Huang, C.; Barlow, S.; Marder, S.R. Perylene-3,4,9,10-tetracarboxylic acid diimides: Synthesis, physical properties, and use in organic electronics. J. Org. Chem. 2011, 76, 2386-2407. [CrossRef]

11. Würthner, F.; Stolte, M. Naphthalene and perylene diimides for organic transistors. Chem. Commun. 2011, 47, 5109-5115. [CrossRef] [PubMed]

12. Zhang, X.; Rehm, S.; Safont-Sempere, M.M.; Würthner, F. Vesicular perylene dye nanocapsules as supramolecular fluorescent ph sensor systems. Nat. Chem. 2009, 1, 623-629. [CrossRef] [PubMed]

13. Calzado, E.M.; Villalvilla, J.M.; Boj, P.G.; Quintana, J.A.; Gómez, R.; Segura, J.L.; Díaz-García, M.A. Effect of structural modifications in the spectral and laser properties of perylenediimide derivatives. J. Phys. Chem. C 2007, 111, 13595-13605. [CrossRef]

14. Li, Y.; Zhu, L.; Fan, Y.; Li, Y.; Cheng, L.; Liu, W.; Li, X.; Fan, X. Formation and controlled drug release using a three-component supramolecular hydrogel for anti-schistosoma japonicum cercariae. Nanomaterials 2016, 6, 46. [CrossRef] [PubMed]

15. Sharma, G.D.; Balraju, P.; Mikroyannidis, J.A.; Stylianakis, M.M. Bulk heterojunction organic photovoltaic devices based on low band gap small molecule btd-tnp and perylene-anthracene diimide. Sol. Energy Mater. Sol. Cells 2009, 93, 2025-2028. [CrossRef]

16. Wicklein, A.; Ghosh, S.; Sommer, M.; Würthner, F.; Thelakkat, M. Self-assembly of semiconductor organogelator nanowires for photoinduced charge separation. ACS Nano 2009, 3, 1107-1114. [CrossRef]

17. Würthner, F.; Chen, Z.; Dehm, V.; Stepanenko, V. One-dimensional luminescent nanoaggregates of perylene bisimides. Chem. Commun. 2006, 1188-1190. [CrossRef]

18. Tuccitto, N.; Delfanti, I.; Torrisi, V.; Scandola, F.; Chiorboli, C.; Stepanenko, V.; Würthner, F.; Licciardello, A. Supramolecular self-assembled multilayers of terpyridine-functionalized perylene bisimide metal complexes. Phys. Chem. Chem. Phys. 2009, 11, 4033-4038. [CrossRef]

19. Chen, Z.; Fimmel, B.; Würthner, F. Solvent and substituent effects on aggregation constants of perylene bisimide $\pi$-stacks-A linear free energy relationship analysis. Org. Biomol. Chem. 2012, 10, 5845-5855. [CrossRef]

20. Li, X.-Q.; Stepanenko, V.; Chen, Z.; Prins, P.; Siebbeles, L.D.A.; Würthner, F. Functional organogels from highly efficient organogelator based on perylene bisimide semiconductor. Chem. Commun. 2006, 3871-3873. [CrossRef]

21. Li, X.-Q.; Zhang, X.; Ghosh, S.; Würthner, F. Highly fluorescent lyotropic mesophases and organogels based on j-aggregates of core-twisted perylene bisimide dyes. Chem. Eur. J. 2008, 14, 8074-8078. [CrossRef] [PubMed]

22. Würthner, F.; Bauer, C.; Stepanenko, V.; Yagai, S. A black perylene bisimide super gelator with an unexpected j-type absorption band. Adv. Mater. 2008, 20, 1695-1698. [CrossRef]

23. Stepanenko, V.; Li, X.-Q.; Gershberg, J.; Würthner, F. Evidence for kinetic nucleation in helical nanofiber formation directed by chiral solvent for a perylene bisimide organogelator. Chem. Eur. J. 2013, 19, 4176-4183. [CrossRef] [PubMed]

24. Liu, H.; Shen, L.; Cao, Z.; Li, X. Covalently linked perylenetetracarboxylic diimide dimers and trimers with rigid "J-type" aggregation structure. Phys. Chem. Chem. Phys. 2014, 16, 16399-16406. [CrossRef] [PubMed]

25. Kaiser, T.E.; Wang, H.; Stepanenko, V.; Würthner, F. Supramolecular construction of fluorescent j-aggregates based on hydrogen-bonded perylene dyes. Angew. Chem. 2007, 119, 5637-5640. [CrossRef]

26. Yagai, S.; Seki, T.; Karatsu, T.; Kitamura, A.; Würthner, F. Transformation from h- to j-aggregated perylene bisimide dyes by complexation with cyanurates. Angew. Chem. 2008, 120, 3415-3419. [CrossRef]

27. Herbst, S.; Soberats, B.; Leowanawat, P.; Lehmann, M.; Würthner, F. A columnar liquid-crystal phase formed by hydrogen-bonded perylene bisimide j-aggregates. Angew. Chem. 2017, 129, 2194-2197. [CrossRef]

28. Gan, S.; Zhong, L.; Engelbrekt, C.; Zhang, J.; Han, D.; Ulstrup, J.; Chi, Q.; Niu, L. Graphene controlled h- and j-stacking of perylene dyes into highly stable supramolecular nanostructures for enhanced photocurrent generation. Nanoscale 2014, 6, 10516-10523. [CrossRef]

29. Ghosh, S.; Li, X.-Q.; Stepanenko, V.; Würthner, F. Control of h- and j-type $\pi$ stacking by peripheral alkyl chains and self-sorting phenomena in perylene bisimide homo- and heteroaggregates. Chem. Eur. J. 2008, 14, 11343-11357. [CrossRef]

30. Zhao, J.-S.; Ruan, Y.-B.; Zhou, R.; Jiang, Y.-B. Memory of chirality in j-type aggregates of an achiral perylene dianhydride dye created in a chiral asymmetric catalytic synthesis. Chem. Sci. 2011, 2, 937-944. [CrossRef] 
31. Li, Y.; He, Y.; Tong, X.; Wang, X. Photoinduced deformation of amphiphilic azo polymer colloidal spheres. J. Am. Chem. Soc. 2005, 127, 2402-2403. [CrossRef] [PubMed]

32. Hu, Q.; Wang, Y.; Jia, J.; Wang, C.; Feng, L.; Dong, R.; Sun, X.; Hao, J. Photoresponsive chiral nanotubes of achiral amphiphilic azobenzene. Soft Matter 2012, 8, 11492-11498. [CrossRef]

33. Gopal, A.; Hifsudheen, M.; Furumi, S.; Takeuchi, M.; Ajayaghosh, A. Thermally assisted photonic inversion of supramolecular handedness. Angew. Chem. Int. Ed. 2012, 51, 10505-10509. [CrossRef] [PubMed]

34. Hayasaka, H.; Miyashita, T.; Nakayama, M.; Kuwada, K.; Akagi, K. Dynamic photoswitching of helical inversion in liquid crystals containing photoresponsive axially chiral dopants. J. Am. Chem. Soc. 2012, 134, 3758-3765. [CrossRef] [PubMed]

35. Miao, T.; Yin, L.; Cheng, X.; Zhao, Y.; Hou, W.; Zhang, W.; Zhu, X. Chirality construction from preferred $\pi-\pi$ stacks of achiral azobenzene units in polymer: Chiral induction, transfer and memory. Polymers 2018, 10, 612. [CrossRef] [PubMed]

36. Koumura, N.; Kudo, M.; Tamaoki, N. Photocontrolled gel-to-sol-to-gel phase transitioning of meta-substituted azobenzene bisurethanes through the breaking and reforming of hydrogen bonds. Langmuir 2004, 20, 9897-9900. [CrossRef]

37. Mun, G.; Choi, H.; Im, N.; Ahn, J.; Park, J.; Seo, H.; Choi, Y.; Lee, J.H.; Jung, J.H. Retracted article: Spatially resolved mechanical properties of photo-responsive azobenzene-based supramolecular gels. RSC Adv. 2017, 7, 26827-26833. [CrossRef]

38. Mahesh, S.; Gopal, A.; Thirumalai, R.; Ajayaghosh, A. Light-induced ostwald ripening of organic nanodots to rods. J. Am. Chem. Soc. 2012, 134, 7227-7230. [CrossRef]

39. Yagai, S.; Yamauchi, M.; Kobayashi, A.; Karatsu, T.; Kitamura, A.; Ohba, T.; Kikkawa, Y. Control over hierarchy levels in the self-assembly of stackable nanotoroids. J. Am. Chem. Soc. 2012, 134, 18205-18208. [CrossRef]

40. Zhang, W.; Yoshida, K.; Fujiki, M.; Zhu, X. Unpolarized-light-driven amplified chiroptical modulation between chiral aggregation and achiral disaggregation of an azobenzene-alt-fluorene copolymer in limonene. Macromolecules 2011, 44, 5105-5111. [CrossRef]

41. Nguyen, T.-T.-T.; Türp, D.; Wang, D.; Nölscher, B.; Laquai, F.; Müllen, K. A fluorescent, shape-persistent dendritic host with photoswitchable guest encapsulation and intramolecular energy transfer. J. Am. Chem. Soc. 2011, 133, 11194-11204. [CrossRef] [PubMed]

42. Ma, L.; Jia, J.; Yang, T.; Yin, G.; Liu, Y.; Sun, X.; Tao, X. Light-controlled self-assembly and conductance: From nanoribbons to nanospheres. RSC Adv. 2012, 2, 2902-2908. [CrossRef]

43. Zhou, J.; Zhao, Y.; Yu, K.; Zhou, X.; Xie, X. Synthesis, thermal stability and photoresponsive behaviors of azobenzene-tethered polyhedral oligomeric silsesquioxanes. New J. Chem. 2011, 35, 2781-2792. [CrossRef]

44. Sasaki, T.; Ikeda, T.; Ichimura, K. Photoisomerization and thermal isomerization behavior of azobenzene derivatives in liquid-crystalline polymer matrixes. Macromolecules 1993, 26, 151-154. [CrossRef]

45. Sin, S.L.; Gan, L.H.; Hu, X.; Tam, K.C.; Gan, Y.Y. Photochemical and thermal isomerizations of azobenzene-containing amphiphilic diblock copolymers in aqueous micellar aggregates and in film. Macromolecules 2005, 38, 3943-3948. [CrossRef]

(C) 2019 by the authors. Licensee MDPI, Basel, Switzerland. This article is an open access article distributed under the terms and conditions of the Creative Commons Attribution (CC BY) license (http://creativecommons.org/licenses/by/4.0/). 